\title{
UMA BREVE INCURSÃO SOBRE AS ARTES PLÁSTICAS NA OBRA DE MACHADO DE ASSIS
}

\author{
A BRIEF INCURSION INTO THE FINE ARTS IN \\ MACHADO DE ASSIS'S WORK
}

\author{
André Teixeira Cordeiro
}

Resumo: Pretendemos destacar a relação entre literatura e artes visuais em Machado de Assis, a partir das obras de Roger Bastide, Thomas Sträter e Alexandre Eulálio. Um dos recursos machadianos é a economia das descrições desnecessárias, empregando, muitas vezes, obras de arte visual para despertar as lembranças-telas de seu leitor. Tal uso da visualidade se faz tanto pela descrição ou citação de pinturas, gravuras e fotografias, quanto a partir de procedimentos próprios da pintura ou da fotografia que estruturam a obra literária.

Palavras-chave: Machado de Assis, artes visuais, diálogo.

AвstRACt: Based on the concepts and perspectives of Bastide, Thomas Sträter and Alexandre Eulalio, we intend to highlight the relationship between literature and visual arts in Machado de Assis. One of Machado's device is the economy of unnecessary descriptions, employing often works of visual art to awaken the memories-screens of his reader. Such use of visuality is done either by description or citation paintings, engravings and photographs, as from typical procedures of painting or photography that structure literary work.

KEYwords: Machado de Assis, visual arts, dialogue.

\footnotetext{
"Professor adjunto na Universidade Federal do Tocantins, atua no curso de Mestrado em Letras (campus de Araguaína) e na graduação em Pedagogia (campus de Tocantinópolis). Email: andrecordeiro@uft.edu.br
} 
No presente trabalho, destacamos a possibilidade de uma reflexão acerca das artes pictóricas no âmbito da obra de Machado de Assis. Muitos textos machadianos, sejam eles romances, contos ou poemas, abrem-se para produtivos diálogos com textos não-verbais. As referências a imagens em sua obra servem, muitas vezes, para atrair o leitor e despertar as "lembranças-telas". O termo é proposto por Jouve (2000, p. 118) ao se referir ao processo em que ocorre a identificação entre o leitor e os aspectos do texto.

No livro Histórias de quadros e leitores, organizado por Lajolo (2006), temos uma reunião de nove contos de escritores brasileiros, como Ferreira Gullar, Moacyr Scliar, Ana Maria Machado, Luiz Ruffato. Eles criaram suas narrativas através de imagens, sejam elas pinturas, fotografias ou cartuns. Foram nove, também, os artistas visuais que lhes deram suporte, como Benedito Calixto, JeanBaptiste Debret, Odete Maria Ribeiro e Lasar Segall. Acreditamos que estas possibilidades interpretativas permitem estimular o público à leitura e, ao mesmo tempo, oferecem novas possibilidades de compreensão dos signos visuais, abrindo espaço para o imaginário.

Contudo, é na apresentação do livro, realizada por Lajolo, que concentraremos nossa atenção. Intitulando-a de "A pintura é poesia muda e poesia é pintura que fala", ela faz referência ao famoso pensamento do grego Simonides de Cós. Marisa destaca o "Soneto circular" de Machado de Assis, no qual o autor faz referência ao quadro $A$ dama do livro, do pintor italiano Roberto Fontana. Machado retrata uma bela mulher ruiva com um livro pousado no colo:

\section{Soneto circular}
A bela dama ruiva e descansada, De olhos longos, macios e perdidos, Co'um dos dedos calçados e compridos Marca a recente página fechada.

Cuidei que, assim pensando, assim colada Da fina tela aos flóridos tecidos, Totalmente calados os sentidos, Nada diria, totalmente nada.

Mas, eis da tela se despega e anda, E diz-me: - "Horácio, Heitor, Cibrão, Miranda, C. Pinto, X. Silveira, F. Araújo,

Mandam-me aqui para viver contigo." Ó bela dama, a ordens tais não fujo. Que bons amigos são! Fica comigo.

\section{(ASSIS apud LAJOLO 2006, p. 8)}

O soneto nos remete a uma obra visual, determinante para a sua composição. Tratase de um texto, pelo menos nas duas primeiras estrofes, de caráter ecfrástico. A ecfrase, segundo HANSEN (2006), é a "exposição" ou "descrição" de uma obra de arte pela literatura - o conceito remonta à antiguidade em obras como a de Luciano de Samósota e a mais conhecida ecfrase é a descrição do escudo de Aquiles por Homero na Ilíada.

Já os tercetos não são descritivos, mas, ainda assim, tomam o texto não-verbal como ponto de partida ou referência para a sua composição. Nesse caso, partindo das ideias de Cluwer (1997), o poema também se aproximaria do termo alemão Bildgedichte - poemas que verbalizam obras plásticas ou apenas partem delas.

$\mathrm{Na}$ primeira estrofe, através de uma descrição do quadro, Machado identifica "a 
bela dama ruiva e descansada". E em detalhe, o criador de Capitu, concentra-se no seu olhar: uma mulher de "olhos longos, macios e perdidos." Assim, o autor nos leva a entender que ela se encontra em postura de provável reflexão, devido também a sua atitude quando "marca a recente página fechada".

Segundo Lajolo (2006), amigos de Machado de Assis deram-lhe a tela de presente e ele, em agradecimento, lhes dedicou o soneto enviando uma cópia a cada um dos mencionados nos versos 10 e 11. Um deles encarregou-se de publicá-lo, no dia 18 de abril de 1895, em A Gazeta de Notícias, jornal carioca de grande prestígio. Tornando, assim, público o agradecimento do escritor.

A autora justifica que o interesse despertado pela tela se deu quando Machado de Assis, passeando pela Rua do Ouvidor, se depara com o bonito quadro na vitrine de uma loja e "talvez naquele dia Machado estivesse acompanhado por um amigo, que testemunhou seu encanto pela pintura. Ou talvez tivesse comentado com outro seu fascínio pela tela" (LAJOLO, 2006, p. 9). Hoje, o quadro faz parte do acervo machadiano, na Academia Brasileira de Letras, no Rio de Janeiro.

Destacamos que o soneto não se limita a descrever a dama, mas inventa uma história para o quadro e também para o gesto dos amigos. Como que para sublinhar a delicadeza do presente, o narrador dá voz à imagem representada na tela. Em sua imaginação, a dama desprega-se do quadro, caminha até ele e transmite o recado dos amigos, pois foi por eles enviada para fazer companhia ao escritor. Neste soneto, Machado de Assis dá pistas de um universo fecundo entre a arte da palavra e a arte da imagem em sua obra.

Em seu primeiro romance, Ressurreição, publicado originalmente em 1872, temos alusão à presença de imagem quando o personagem Luis Batista descreve um capricho de sua amante e a semelhança desta com uma gravura:

[...] Estamos nesse caso. Ela é extremamente caprichosa, e mais ainda que caprichosa, é amante de coisas d’arte. Há dias fui achá-la aborrecida. Interroguei-a; nada me quis dizer. Pela conversa adiante falou-me duas ou três vezes numa gravura que vira na Rua do Ouvidor, e que o dono vendera quando ela lá voltou, disposta a comprá-la. O assunto era o mais ortodoxo possível: a Israelita Betsabé no banho e o rei Davi a espreitá-la do seu eirado. [...] A gravura creio que era finíssima; mas tinha, além disso, um merecimento para a pessoa de quem lhe falo: é que a figura de Betsabé era a cópia exata das suas feições (ASSIS, 1994, p. 66-67).

Destacamos a princípio nessa passagem, a referência a Rua do Ouvidor, local no qual a gravura fora vista e, a partir daí, desejada. Relacionando esse fato à história do "Soneto Circular", percebemos que esta rua era, realmente, um lugar comum à compra de cópias de quadros de pintores famosos. A via era o grande cenário do final do século XIX no Rio de Janeiro. Toda a agitação se concentrava nela: as lojas mais chiques, as livrarias, as discussões intelectuais nas confeitarias.

Além disso, a Rua do Ouvidor era também a rua dos jornais e a lista de folhas que tiveram suas redações naquele endereço era 
extensa. O local se tornou um ponto de honra para um jornal que almejasse bom conceito e respeito de seus leitores. Nessa rua foi fundada a Academia Brasileira de Letras, em 1896.

Além da alusão à rua, temos no trecho transcrito a referência a uma gravura com o seguinte tema: o banho de Betsabé e o rei Davi a espreitá-la. A referência a esta imagem é capaz de produzir no leitor um conjunto de significações e de relações entre a história bíblica representada e a obra de Machado de Assis em questão. Quando a obra pictórica adentra o texto literário ela traz uma carga simbólica marcante. A princípio, parece apenas uma mera gravura sendo citada, mas se houver uma pesquisa mais detalhada no enredo bíblico no livro de II Samuel, o leitor tem uma grata surpresa.

O rei Davi observou uma mulher casada no banho, apaixonou-se por ela e criou uma rede de situações para seu marido, Urias, ser morto no campo de batalha. O marido traído foi chamado ao palácio, o rei ganhou sua confiança e pediu a ele mesmo que entregasse um bilhete ao seu comandante. Neste bilhete, havia um pedido mortal, aquele soldado deveria ser colocado no ponto mais perigoso do combate para, assim, ser abatido pelo inimigo.

O drama de Félix, em Ressurreição, é o seu sentimento de desconfiança doentia. Várias vezes se separará da namorada, Lívia, porque acredita estar sendo traído mas tudo não passa de mera suposição. Os caracteres do personagem são largamente trabalhados por Machado ao longo da obra, para que, na ação definitiva e traumática (romper o casamento na véspera), haja uma correspondência precisa entre atitude e psicologia do personagem. Segundo este autor, é essencial, para a coerência narrativa, que as ações estejam primeiramente no interior dos personagens.

E o surgimento da questão da gravura vem de encontro a este medo de traição (Betsabé traiu Urias com o rei Davi, na ocasião do falecimento do marido já estava até grávida do amante) e no romance, neste momento, também haverá o expediente não de um bilhete, mas de uma carta. Félix, na ocasião da chegada de Luis Batista, receberá uma pequena carta anônima. Nela, fala-se que assim como o primeiro marido de Lívia foi humilhado, trata-se de uma viúva, ele também o seria em poucos meses após o casamento. São insinuações, mas no o espírito desconfiado de Félix elas serão definitivas para um rompimento. Só ao final do romance teremos a certeza, o autor da tal carta tinha sido o mesmo João Batista, um dos muitos admiradores da bela e casta Lívia. E a pretexto de vir pedir a tal gravura a uma amante, deixou na casa de Félix a carta. Cria-se assim, com a gravura, uma série de cruzamentos. O que era apenas um mero pretexto guarda ligações diretas com a narrativa. As obras plásticas, mesmo sendo imagens fixas, vibram incessantemente quando se trata de Machado.

Em alguns de seus textos essa relação é muito evidente, em outros essa inter-relação não fica explícita, mas se faz sem ser mencionada diretamente. Essa característica de Machado de Assis fora abordada por Alexandre Eulálio em "De um capítulo de Esaú e Jacó ao painel do Último baile", 
ensaio que faz parte de seu livro, Tempo reencontrado: ensaios sobre arte e literatura (2012). Nesse texto, Eulálio sublinha a pouca atenção dada ao "levantamento analítico dos contatos que, através do tempo, têm estabelecido entre si pintura e literatura em nosso meio". (EULÁLIO, 2012, p. 139). Como forma de comprovar essa possibilidade de interação, Eulálio apresenta uma análise paralela da tela de Aurélio de Figueiredo conhecida com O último baile da Monarquia e o seu provável modelo operativo, o capítulo XLVIII do romance de Machado de Assis, Esaú e Jacó (1904), intitulado Terpsícore.

A tela pintada por Figueiredo mostra o Baile da Ilha Fiscal. Esse, o último Baile do Império, ocorrido em 09 de novembro de 1889, 6 dias antes da Proclamação da República. O capítulo supracitado do romance machadiano trata da presença de Flora e demais personagens no referido baile.

[...] foi ao baile da ilha Fiscal com a mãe e o pai. Assim também Natividade, o marido e Pedro, assim Aires, assim a demais gente convidada para a grande festa. Foi uma bela idéia do governo, leitor. Dentro e fora, do mar e de terra, era como um sonho veneziano; toda aquela sociedade viveu algumas horas suntuosas, novas para uns, saudosas para outros, e de futuro para todos ou, quando menos, para a nossa amiga Natividade - e para o conservador Batista [...] (ASSIS, 1994, p. 57).

Relacionando o quadro à cena da festa, Eulálio destaca que o leitor poderá identificar nele parte dos personagens do romance, assim escreve:
[...] no centro, um pouco à esquerda, não é difícil identificar Flora, com o leque meio aberto, seu fino perfil que quase cobre o de Pedro; Aires conversa com ambos, irônico e deferente. Bem ao lado, Santos e Natividade na companhia de um conhecido não identificado, e mais além, a robusta silhueta de Dona Cláudia, junto a Baptista, seu marido (EULÁLIO, 2012, p. 130).

A associação que Eulálio estabelece com o quadro possibilita a leitor construir, em sua mente, uma perfeita visualização do mesmo, aqui, podemos, inclusive, dizer que se trata de uma ecfrase, porque o autor descreve detalhadamente o quadro. É como uma tradução da pintura, pois a interpretação permite relacionar imediatamente texto e imagem. Podemos mesmo dizer que se trata de uma explanação iconográfica da tela, visto ser esta uma forma de linguagem visual que utiliza imagens para representar determinado tema.

Dessa maneira, "o curioso relacionamento do texto machadiano com a tela de Figueiredo" configura-se "uma glosa indireta, livremente reconstruída pelo pintor a partir da sugestão daquele texto literário" (EULÁLIO, 2012, p. 141). Essa correspondência estabelecida entre texto e imagem comprova a riqueza plástica do vocabulário de Machado e é um exemplo da forte expressividade imagética desenhada pelo autor através de palavras.

Contudo, as críticas ao escritor, disseminaram-se sobre a sua falta de descrições e o pouco interesse pela paisagem brasileira. Romero (1992, p. 69) indica que no escritor faltava "a imaginação vivace, alada, rápida, 
apreensora, capaz de reproduzir as cenas da natureza ou da sociedade, e daí a sua incapacidade descritiva e seu desprazer pela paisagem." Outros autores "criticaram em Machado a falta da intenção e do colorido nacional [...]" (SCHWARZ, 2002, p. 165). Contudo, podemos afirmar que Machado de Assis sentia sim o seu país, ainda que não o demonstrasse de maneira tão explícita.

Nossa afirmação parte das colocações de Bastide (2006), no ensaio "Machado de Assis, paisagista", no qual declara que a ausência de longas cenas descritivas não deve ser apontada como falta interesse pela paisagem em Machado de Assis, podendo este ser considerado até mais descritivo que qualquer escritor de seu tempo. O sociólogo francês, contrariando a posição da crítica, acentua:

[...] reputo Machado de Assis um dos maiores paisagistas brasileiros, um dos que deram à arte da paisagem na literatura um impulso semelhante ao que se efetuou paralelamente na pintura, e que qualificarei, se me for permitido usar uma expressão 'mallarmiana', de presença, mas presença quase alucinante, de uma ausência. (BASTIDE, 2006, p. 418)

Bastide esclarece, em seu artigo, um fato não percebido pela crítica. A descrição machadiana era diferente, empregava outra técnica, oposta à forma da narrativa romântica. Candido defende essa posição em seu "Esquema de Machado de Assis":

[...] Roger Bastide, que, contrariando uma velha afirmação, segundo a qual Machado não sentiu a natureza do seu país, mostrou que, ao contrário, ele a percebe com penetração e constância; mas em lugar de representá-la pelos métodos do descritivismo romântico, incorpora-a à filigrana da narrativa, como elemento funcional da composição literária. (CÂNDIDO, 1995, p. 21-22)

Dessa forma, para Machado de Assis a natureza exterior funcionava mais como matéria prima para a construção literária do que como simplesmente alvo de descrições explícitas, assim "em lugar de se fazer presente em textos descritivos, 'quadros' estanques, simples molduras para trechos narrativos" (OLIVEIRA, 2011, p. 25), a descrição machadiana faz parte da cena, está na caracterização de seus personagens e em suas ações. Dessa forma, mesmo não descrita diretamente, a pintura afirma uma presença virtual subjacente ao discurso.

A técnica de Machado consiste em evitar descrições prolongadas, encontrando sempre uma forma de inserir o ambiente na trama e nas personagens, de modo que sua presença física se reduzisse ao mínimo necessário para o efeito literário desejado. Nesse sentido, "as descrições podem, naturalmente, existir, mas desde que se reduzam a uma extensão da narrativa em que se enquadram [...]" (BASTIDE, 2006, p. 418). Um exemplo que nos indica um pouco da alusão ao ambiente dentro da narrativa é a metáfora utilizada pelo autor para retratar os olhos de Capitu em Dom Casmurro.

Retórica dos namorados, dá-me uma comparação exata e poética para dizer o que foram aqueles olhos de Capitu. Não me acode imagem capaz de dizer, sem quebra da dignidade do estilo, o 
que eles foram e me fizeram. Olhos de ressaca? Vá, de ressaca. É o que me dá idéia daquela feição nova. Traziam não sei que fluido misterioso e enérgico, uma força que arrastava para dentro, como a vaga que se retira da praia, nos dias de ressaca. Para não ser arrastado, agarrei-me às outras partes vizinhas, às orelhas, aos braços, aos cabelos espalhados pelos ombros; mas tão depressa buscava as pupilas, a onda que saía delas vinha crescendo, cava e escura, ameaçando envolver-me, puxar-me e tragar-me (ASSIS, 1994, p. 32).

O leitor atento perceberá características ambientais nos olhos da personagem e entenderá que as imagens evocadas pelos "olhos de ressaca" remetem à paisagem marinha brasileira. Nesse sentido, Bastide (2006) reflete a respeito da natureza ser também uma personagem e representar o seu papel. Para o autor, é necessário que a paisagem tenha significação e finalidade próprias, servindo para facilitar a compreensão dos homens ou auxiliar o desenrolar da ação, e não se constitua em mero quadro rígido.

Machado é capaz de fazer combinar o mar e a vegetação de forma a integrá-los nos elementos da composição. Lago, citando Bastide, argumenta sobre essa característica machadiana ainda em Dom Casmurro:

\section{[...] o mar banha Dom Casmurro em suas águas salgadas verdes e turvas. [...] Não está somente nos olhos de Capitu [...] mas liga ainda, com a sua branca orla [...] o pedaço de praia entre a Glória e o Flamengo une, com sua areia úmida, sua geografia oceânica e sentimental, a casa de Casmurro e a de Escobar; todos}

os acontecimentos do drama se situam em dois planos estreitamente misturados, doçura da luz na água e nos espíritos, tempestades nos corações e nas águas; constantemente o olhar do leitor é dirigido para as ondas furiosas ou acariciantes. A ligação é tão completa que o ciúme do herói só se precisa pouco a pouco, depois de desviar, de hesitar entre o mar e o amigo; é o mar que se encarregará da vingança [...] (LAGO, 2011, p. 101).

Concordamos que não é apenas através de descrições rigorosas que se mostra um ambiente ao leitor. Na verdade, "[...] sem a menor descrição, sem molduras, sem fundos de quadro, abolidas todas as distâncias, Machado de Assis realiza o milagre de tornar a natureza mais presente do que se a pintasse em longas páginas" (BASTIDE, 2006, p. 425). Dessa forma, podemos inferir que ele descreve sem descrever e o faz muito bem, como podemos evidenciar nesta passagem do conto "O Enfermeiro":

Como o silêncio acabava por aterrar-me, abri uma das janelas, para escutar o som do vento, se ventasse. Não ventava. A noite ia tranquila, as estrelas fulguravam, com a indiferença de pessoas que tiram o chapéu a um enterro que passa, e continuam a falar de outra cousa. Encostei-me ali por algum tempo, fitando a noite, deixando-me ir a uma recapitulação da vida, a ver se descansava da dor presente (ASSIS, 2008, p. 69-70).

Observamos no trecho que, incorporada à estrutura narrativa, a paisagem interioriza-se, ou seja, ele descreve sem fazer paradas 
na narrativa. Nesse sentido, percebemos uma das pinceladas machadianas indicadas por Bastide (2006, p. 425) através da união da paisagem com a caracterização de estado de ânimo do personagem, pois aqui "a natureza se confunde com o herói”. Nesse aspecto, lembramos ainda uma passagem em que Bastide, compara os retratos pintados por Cézanne - para os quais o pintor transpôs as cores da natureza aos personagens, a exemplo da famosa série das banhistas - com a maturidade artística de Machado, momento em que analogamente o autor faz a transposição da paisagem para a psicologia dos personagens.

Pereira (1973, p. 62-63) ofereceu uma explicação sucinta para o método machadiano, quando coloca que a distância que vai "entre fazer ver as pessoas através do ambiente, e deixar perceber o ambiente através das pessoas, Machado de Assis a transpôs serenamente, sem auxílios nem hesitações". A autora, na verdade, explica a capacidade de Machado em apresentar o ambiente por meio dos personagens, sem a necessidade de descrições minuciosas.

Destacamos, nesse sentido, que Machado de Assis, embora perfeitamente capaz de descrições convencionais, prefere dar à paisagem significação e finalidades próprias para desse modo permitir uma maior compreensão dos homens e até mesmo sustentar o desenrolar da ação, e não funcione apenas como um simples quadro rígido. A esse respeito o próprio Machado de Assis esclarece em seu ensaio "Instituto de Nacionalidade":
Não há dúvida que uma literatura, sobretudo uma literatura nascente, deve principalmente alimentar-se dos assuntos que lhe oferece a sua região, mas não estabeleçamos doutrinas tão absolutas que a empobreçam. O que se deve exigir do escritor antes de tudo, é certo sentimento íntimo, que o torne homem do seu tempo e do seu país, ainda quando trate de assuntos remotos no tempo e no espaço (ASSIS, 1999, p. 17-18).

Isto posto, fica claro que deve haver sentimento de nacionalidade por parte do escritor, mas ele não pode empobrecer seu texto dedicando páginas e páginas à descrição. Para o autor, não há necessidade de exageros para exaltar a natureza brasileira, uma vez que "[...] a oportunidade e a simplicidade são cabais para reproduzir uma grande imagem ou exprimir uma grande idéia." (ASSIS, 1999, p. 29). Através da descrição integrada ao discurso, Machado impregna a caracterização das personagens e suas ações.

No conto "D. Benedita", evidenciamos essa possibilidade quando a personagem é caracterizada de forma a ser confrontada com figuras mitológicas: "vê que não lhe dou Vênus; também não lhe dou Medusa. Ao contrário de Medusa, nota-se-lhe o alisado simples do cabelo, preso sobre a nuca." (ASSIS, 2006, p. 87). Percebemos que Machado não se detém a descrevê-la, em vez disso, o autor faz uma descrição do que na verdade não lhe representa, através das figuras citadas.

Ao reportar-se a essas personagens tão conhecidas do leitor, é como se Machado citasse um quadro. Artifício esse utilizado para não se estender em descrições. É como uma 
ecfrase abreviada, pois, através da relação de dona Benedita com as figuras mitológicas, o autor diz que, embora ela não possa ser considerada a deusa do erotismo, da beleza e do amor, na figura de Vênus, também não pode ser comparada a um monstro, na figura de Medusa.

Já no conto "Uma excursão milagrosa", a descrição do personagem Tito é associada à figura de Alcibíades, rapaz extremamente rico e criado perto de pessoas poderosas, além de muitíssimo belo e inteligente. Machado de Assis explora este repertório visual na descrição de seu personagem.

Possuindo um semblante angélico, uns olhos meigos e profundos, o nariz descendente legítimo e direto do de Alcibiades, a boca graciosa, a fronte larga como o verdadeiro trono do pensamento, Tito pode servir de modelo a pintura e de objeto amado aos corações de quinze e mesmo de vinte anos (ASSIS, 1994, p. 2, grifos nossos).

Tito é como Alcibíades, possuidor de brilhantes qualidades, mas com fraquezas de caráter, que diminuem as virtudes que $o$ enobrecem. Mais uma vez, comprovamos a capacidade machadiana em descrever seus personagens a partir da alusão a um personagem histórico.

Evidenciamos também uma relação interarte no romance Quincas Borba, no qual temos alusão à presença das artes visuais na residência de Rubião. Na obra, a referência a personalidades importantes da história, admiradas por seus grandes feitos, tem forte significação.
O barbeiro relanceou os olhos pelo gabinete, onde fazia a principal figura à secretária, e sobre ela os dous bustos de Napoleão e Luís Napoleão. Relativamente a este último, havia ain$\mathrm{da}$, pendentes da parede, uma gravura ou litografia representando a Batalha de Solferino, e um retrato da imperatriz Eugênia (ASSIS, 1994, p. 118, grifos do autor).

O par, presença / ausência sugerido por Bastide na descrição machadiana, ressoa por toda a estrutura do romance e pode ser percebido, no trecho acima, a partir da aproximação da imagem do busto de Napoleão III à imagem de Rubião. O personagem acredita ser o imperador francês e passa a viver conforme a necessidade das aparências, como forma de fugir da realidade e evitar as dores, tal qual a ideia de um mundo sem dor defendida pelo criador do Humanitismo.

Rubião, enlouquecido, acredita ser um vencedor, assim como Napoleão III no combate representado pelo quadro a Batalha de Solferino, um dos maiores combates da segunda guerra de independência da Itália, travado em 24 de junho de 1859. Sua amada Sofia, a esposa do amigo Cristiano Palha, é ninguém menos que a imperatriz Eugênia, mulher possuidora de uma beleza extraordinária.

Gledson (2003) defende que Rubião representa o povo brasileiro, mostrando através da vida desse personagem uma alegoria do próprio Império e dos conflitos e dilemas que a sociedade brasileira desse período estava vivenciando e dos quais não tinha plena consciência. Assim, a loucura de Rubião corresponderia à perda de identidade brasileira e a sua atitude em relação ao progresso. 
Em Esaú e Jacó, Machado faz referência a retratos de dois inimigos na história da França para retratar o constante embate entre os irmãos Pedro e Paulo:

Tanto cresceram as opiniões de Pedro e Paulo que, um dia, chegaram a incorporar-se em alguma coisa. Iam descendo pela Rua da Carioca. Havia ali uma loja de vidraceiro, com espelhos de vário tamanho, e, mais que espelhos, também tinha retratos velhos e gravuras baratas, com e sem caixilho. Pararam alguns instantes, olhando à toa. Logo depois, Pedro viu pendurado um retrato de Luís XVI, entrou e comprou-o por oitocentos réis; era uma simples gravura atada ao mostrador por um barbante. Paulo quis ter igual fortuna, adequada às suas opiniões, e descobriu um Robespierre (ASSIS, 1994, p. 29).

Através das imagens de Luís XVI e Robespierre, referentes a Pedro e Paulo respectivamente, Machado insinua o perfil de personalidade de seus personagens. Há certa relação de espelhamento entre a representação dos personagens com as imagens apresentadas, ou pelo menos os personagens buscam identificação com as figuras retratadas. Robespierre (1758-1794) foi um dos mais conhecidos líderes da Revolução Francesa, e Luís XVI (1754-1793) foi deposto e decapitado por essa revolução. Essa evidência acentua a relação entre os irmãos que brigavam ainda no ventre, depois, pelo amor de Flora, assim como pelos retratos, pela política, por tudo.

As obras artísticas, frequentemente mencionadas por Machado, concebem um espaço das artes visuais em sua literatura. Além disso, elas servem também para descrever a sua relação com a revolucionária técnica, sua contemporânea, de captar a realidade: a fotografia (STRÄTER, 2009). Em Dom Casmurro, a fotografia "vai ter a função crucial de ser para Bentinho a última e decisiva prova da (suposta) traição da esposa, Capitu, com o amigo Escobar" (STRÄTER, 2009, p. 116). Encontramos nesse romance algumas alusões a retratos fotográficos, contudo, nos ateremos ao retrato de Escobar, descrito da seguinte forma:

Uma só vez olhei para o retrato de Escobar. Era uma bela fotografia tirada um ano antes. Estava de pé, sobrecasaca abotoada, a mão esquerda no dorso de uma cadeira, a direita metida ao peito, o olhar ao longe para a esquerda do espectador. Tinha garbo e naturalidade. A moldura que lhe mandei pôr não encobria a dedicatória, escrita embaixo, não nas costas do cartão: 'Ao meu querido Bentinho o seu querido Escobar 20-4-70 (ASSIS, 1994, p. 110).

Essa descrição da fotografia de Escobar revela "uma tentativa de ler, nas imagens, o seu significado." Atitude essa praticável no capítulo intitulado Fotografia, no qual esse objeto se torna "determinante na narrativa" (CARVALHO, 2011, p. 61). Entendamos o porquê no pequeno capítulo transcrito a seguir:

Palavra que estive a pique de crer que era vítima de uma grande ilusão, uma fantasmagoria de alucinado; mas a entrada repentina de Ezequiel, gritando: — "Mamãe! Mamãe! É hora da missa!" Restituiu-me à consciência da realidade. Capitu e eu, involuntariamente, olhamos para a fotografia de Escobar, e depois um para o outro. Desta vez a 
confusão dela fez-se confissão pura. Este era aquele; havia por força alguma fotografia de Escobar pequeno que seria o nosso pequeno Ezequiel. De boca, porém, não confessou nada; repetiu as últimas palavras, puxou do filho e saíram para a missa (ASSIS, 1994, p. 122) (grifos nossos).

Bentinho, pela comparação entre a figura real do garoto neste momento de espontaneidade com a fotografia de Escobar, parece ter encontrado a resposta: Capitu o traiu, Ezequiel era realmente filho de Escobar. A resposta ele só encontra através da fotografia e o que sustentaria, mais ainda, esta prova seria uma outra fotografia: a imagem de Escobar pequeno. Nesse sentido, retomamos Barthes (1984, p. 153), quando menciona que "a fotografia, às vezes, faz parecer o que jamais percebemos de um rosto real: um traço genético, o pedaço de si mesmo ou de um parente que vem de um ascendente". Mesmo com a semelhança, Bentinho parece ainda guardar a dúvida, só a outra fotografia confirmaria completamente aquela traição. Mesmo na suposta certeza, acena-se, ainda, com o poder definitivo e revelador propiciado pela fotografia.

A fotografia também aparece como uma metáfora em textos de Machado de Assis como forma de "retratar a alma das pessoas" (STRÄTER, 2009, p. 113). No conto "Espelho", esse fato se dá quando o protagonista Jacobina procura expressar uma teoria sobre a existência de duas almas interligadas, a interior e a exterior. A primeira pode ser entendida como a verdadeira maneira como nos enxergamos e a segunda como os outros nos enxergam. Nas palavras de Machado (2006, p. 136), "cada criatura humana traz duas almas consigo: uma que olha de dentro para fora, outra que olha de fora para dentro..."

Para comprovar essa teoria, o narrador protagonista conta uma história passada em sua juventude, quando havia recebido o título de alferes. Convidado a passar uns dias no sítio da tia Marcolina, só para ela ter a honra de receber em suas terras um alferes. Ele ganha dela um espelho, "um grande espelho, obra rica e magnífica [...]” (ASSIS, 2006, p. 138), que, em dado momento de solidão sem ninguém para elogiar seu cargo e principalmente sua farda, servirá como uma fotografia devolvendo-lhe a imagem perdida.

O espelho funciona aqui como uma fotografia, na qualidade de retratar o status social num certo momento da vida como um documento, como evidência, atestado de uma preexistência da coisa fotografada, afirmação da posição atingida na sociedade, pela qual o homem moderno se define (STRÄTER, 2009, p. 121).

Como uma fotografia da alma humana o espelho passa a ser um documento capaz de retratar o status social do personagem. Na verdade, Machado queria nos dizer que, em nosso meio, a alma externa, ligada ao status, ao prestígio social, representa mais que a alma interna, a nossa real personalidade. Candido (1995, p. 24) menciona que nesse conto "a integridade pessoal estava, sobretudo, na opinião e manifestações dos outros." E acrescenta que Machado objetiva mostrar que sem essa máscara "nada somos." 
Em “Cantiga de esponsais”, além de evocar sua outra irmã, a música, a literatura machadiana "convida o leitor com sua técnica de espectador a presenciar na imaginação uma cena ambientada na época em que o Brasil era colônia” (STRÄTER, 2009, p. 122). Para tanto, o narrador conduz a cena num sentido fotográfico em que a câmara segue os passos de Romão Pires.

[...] Não lhe chamo a atenção para os padres e os sacristães, nem para o sermão, nem para os olhos das moças cariocas, que já eram bonitos nesse tempo, nem para as mantilhas das senhoras graves, os calções, as cabeleiras, as sanefas, as luzes, os incensos, nada. Não falo sequer da orquestra, que é excelente; limito-me a mostrar-lhes uma cabeça branca, a cabeça desse velho que rege a orquestra com alma e devoção. [...] Chama-se Romão Pires; terá sessenta anos, não menos, [...] Quem não conhecia mestre Romão, com o seu ar circunspecto, olhos no chão, riso triste, e passo demorado? Tudo isso desaparecia à frente da orquestra; então a vida derramava-se por todo o corpo e todos os gestos do mestre; o olhar acendia-se, o riso iluminava-se: era outro (ASSIS, 205, p. 47-48, grifos nossos).

A cena descrita inicialmente nos leva a recorrer ao punctum de Barthes (1984), algo que salta da fotografia como uma flecha, quando o narrador menciona limitar-se a mostrar o detalhe da cabeça do velho. A partir da descrição fotográfica da cena, o leitor visualiza Romão Pires à frente de sua orquestra. Primeiro observamos a cena num plano amplo e aberto, depois num plano médio e a seguir num plano fechado (close-up).

A relação entre a arte literária e a fotografia configura-se em Memorial de Aires, moldada através das anotações íntimas recolhidas do diário do Conselheiro Aires. Entendemos que o diário congela a realidade, tanto quanto a fotografia é capaz de fazê-lo. Dessa forma, nesse romance, Machado torna visível o que é do âmbito do invisível. Como exemplo, citamos uma passagem registrada no dia 30 de julho de 1888.

[...] e das saudades que ela foi achar lá, das lembranças que lhe acordaram as paredes dos quartos e das salas, as colunas da varanda, as pedras da cisterna, as janelas antigas, a capela rústica. Mucamas e moleques deixados pequenos e encontrados crescidos, livres com a mesma afeição de escravos, têm algumas linhas naquelas memórias de passagem. Entre os fantasmas do passado, o perfil da mãe, ao pé o do pai, e ao longe como ao perto, nas salas como no fundo do coração, o perfil do marido, tão fixo que cheguei a vê-lo [...] (ASSIS, 1994, p. 38).

Trata-se da referência a uma carta escrita pela viúva Noronha, endereçada ao um casal de amigos na Corte, na qual ela compartilha o reencontro com o pai enfermo, de quem um dia se afastou por contrariá-lo na escolha do marido. Em outra passagem temos alusão à fotografia quando o narrador personagem anota em seu diário que "Fidélia mandou encaixilhar juntas as fotografias do pai e do marido, e pô-las na sala." (ASSIS, 1994, p. 49). Naquelas simples fotos estão impressas uma realidade capturada com a 
câmara fotográfica, o que no dizer de Walter Benjamim "ver uma beleza nova naquilo que esta desaparecendo" (SONTAG, 1981, p. 75). A fotografia, nesse sentido, reproduz um instante do presente que já se tornou passado.

De todo o exposto, não nos resta dúvidas da capacidade machadiana em descrever mesmo evitando descrições desnecessárias, restringindo-as aos momentos em que tem mais efeito sobre o enredo e sobre a compreensão das personagens. Como declara SCHWARZ (2002, p. 166), "em vez de elementos de identificação, Machado buscava relações e formas. A feição nacional destas é profunda, sem ser óbvia." Desse modo, entendemos que uma leitura atenta da obra machadiana nos permite perceber que as artes visuais fazem parte da cena e propiciam um campo fecundo de interpretação para o leitor atento.

\section{BibLIOGRAFIA}

ASSIS, Machado de. Instinto de nacionalidade \& outros ensaios. Porto Alegre: Mercado de Letras, 1999.

. Obra Completa, Rio de Janeiro: Editora Nova Aguilar, 1994. Disponível em http://machado.mec.gov.br/index.php/obracompleta-menu-principal-173/164-romance, acesso em 12/12/2013.

BARTHES, Roland. A câmera clara: nota sobre a fotografia. Tradução de Júlio Castañon Guimarães. Rio de Janeiro: Nova Fronteira, 1984.

BASTIDE, Roger. Machado de Assis paisagista. Revista Teresa, n. 6/7. São Paulo: Editora 34/ Imprensa Oficial, 2006.
CÂNDIDO, Antonio. Vários escritos. $3^{\mathrm{a}}$. ed. revista e ampliada. São Paulo: Duas Cidades, 1995.

CLAUS, Clüver. Estudos interartes. Literatura e sociedade, São Paulo, SP, n.2, p. 37-55. 1997.

CARVALHO, Carolina Sá. Fotografia e Fantasmagoria em Dom Casmurro. Machado de Assis em linha, ano 4, número 8, dezembro 2011. Disponível em: http://machadodeassis. net/revista/numeroo8/rev_num08_artigoo4. pdf. Acesso em: 22 abr. 2014.

EULÁLIO, Alexandre. Tempo reencontrado: ensaios sobre arte e literatura. Organização de Carlos Augusto Calil. São Paulo: Instituto Moreira Salles; Editora 34, 2012.

GLEDSON, John. Machado de Assis: ficção e história. 2 ed. Ver. São Paulo: Paz e Terra, 2003. HANSEN, João Adolfo. Categorias epidíticas da ekphrasis. Revista USP, São Paulo, SP, n. 71, p. 85-105, set. / nov. 2006. Disponível em: http:// www.usp.br/revistausp/71/10-joaoadolfo.pdf. Acesso em: 15 nov. 2015.

LAGO, Sylvio. Contrastes e Convergências: estudos de literatura comparada. Biblioteca 24 horas, 2011.

LAJOLO, Marisa. Historias de Quadros e Leitores. Série Imagem \& Texto. Antologia de contos contemporâneos. São Paulo: Moderna, 2006.

JOUVE, Vincent. A leitura. São Paulo, UNESP, 2002.

OLIVEIRA, Solange Ribeiro de. As artes na ficção de Machado de Assis: pintura, teatro, música. Pós: Belo Horizonte, v. 1, n. 2, p. 24 38. 2011.

PEREIRA, Lucia Miguel. História da literatura brasileira: Prosa de fiç̧ão (1870 a 1920). Rio de Janeiro: José Olympio; Brasília, INL, 1973. 
SCHWARZ. Roberto. Que horas são? Ensaios: Duas notas sobre Machado de Assis. São Paulo. Companhia das Letras, 2002.

SONTAG, Susan. Sobre fotografia. Tradução de Rubens Figueiredo. São Paulo: Companhia das Letras, 2004.

STRÄTER, Thomas. De retratos, espelhos e reproduções: o olhar fotográfico de Machado de Assis. In: ANTUNES, Benedito; MOTTA, Sérgio Vicente (Orgs.). Machado de Assis e a crítica internacional. São Paulo: Editora Unesp, 2009.

Recebido para publicação em 20 nov. 2015.

Aceito para publicação em 18 ago. 2016. 